\title{
Obstructive Sleep Apnea Knowledge Among Dentists and Physicians
}

\author{
Michael Simmons, DMD, MSc, MPH ${ }^{1,}$; James Sayre, DrPH, MS ${ }^{1}$; Helena M. Schotland, MD ${ }^{2}$; Donna B. Jeffe, PhD ${ }^{3}$ \\ ${ }^{1}$ University of California at Los Angeles, School of Public Health, Los Angeles, California, USA; ${ }^{2}$ Department of Medicine, University \\ of Michigan School of Medicine, Ann Arbor, Michigan, USA; '3 Department of Medicine, Washington University in St. Louis School of \\ Medicine, St. Louis, Missouri, USA
}

\begin{abstract}
Study Objectives: Obstructive sleep apnea (OSA) is a largely undiagnosed and untreated sleep disorder with public health implications. This study investigated whether dentists were as knowledgeable about OSA as physicians.

Methods: Two convenience samples of California dentists were surveyed online ( $N=107)$ and in-person (N=63) between January and April 2019 using the 18 knowledge items from the validated Obstructive Sleep Apnea Knowledge and Attitudes (OSAKA) Questionnaire. California dentists' total score was then compared to a compilation of published physicians' total OSA-knowledge scores from 12 studies (2003-2020) using Chi-square tests with Bonferroni adjusted $p<0.0023$. OSA-knowledge gaps and competencies were also compared on individual item data provided for nine of the published physician studies.

Results: Mean total correct OSA-knowledge scores were $73.6 \%$ for California dentists $(\mathrm{N}=170)$ and $63.9 \%$ across all physicians $(\mathrm{N}=2,559)$; scores were $84.5 \%$ for Canadian otolaryngology residents $(\mathrm{N}=66), 75.6 \%$ for U.S. physicians $(\mathrm{N}=305)$, and $62.3 \%$ for all other non-U.S. physicians $(\mathrm{N}=2,188)$. The all-physician group had more knowledge gaps than dentists.

Conclusion: Dentists had noninferior knowledge of OSA compared with most physician groups. Findings suggest that dentists may serve to increase the number of healthcare providers able to identify and treat patients with OSA, mitigating this healthcare gap. Suboptimal sleep medicine and OSA training in medical and dental education remains a challenge, perpetuating the public health ramifications of underdiagnosed and undertreated OSA.

Clinical Implications: Engaging more dentists to identify patients at risk for OSA at the point of care and treat or refer patients for treatment, as appropriate, helps meet this public health need.

Keywords: dental public health; dentists; educational measurement; physicians; schools; sleep apnea, obstructive

Citation: Simmons M, Sayre J, Schotland HM, Jeffe DB. Obstructive sleep apnea knowledge among dentists and physicians. J Dent Sleep Med. 2021;8(4)
\end{abstract}

\section{INTRODUCTION}

Obstructive sleep apnea (OSA) has been described as "an unmet public health problem". 1 Increasing the proportion of people with OSA symptoms being evaluated is one of only three Healthy People 2020 listed populationlevel sleep health goals from the Office of Disease Prevention and Health Promotion of the US Department of Health and Human Services. ${ }^{2}$ Although some OSA is associated with significant morbidity and mortality, ${ }^{3-5}$ only a small percentage of OSA cases are diagnosed. ${ }^{6,7}$ Thus, training a greater number of primary healthcare providers (PHPs) to identify patients at risk for OSA at the point of care is important. Because most portals of entry into diagnosis are through physicians, many patients in whom OSA is diagnosed also are treated first with the current gold standard therapy, continuous positive airway pressure (CPAP). ${ }^{8}$ Unfortunately, as reported in a systematic review of 20 years of research, CPAP therapy has a history of poor compliance, ${ }^{9}$ and results of several trials reported no significant effect of CPAP on reducing adverse cardiovascular outcomes in patients with OSA but without excessive daytime sleepiness. ${ }^{10-13}$

Addressing the public health problem of undiagnosed and untreated OSA is particularly daunting, as almost 1 billion people worldwide are affected by OSA. ${ }^{14}$ There is consequently a global public health need for effective population-level diagnostic and treatment strategies to address the challenges of identifying and managing OSA at its various levels of complexity to help mitigate costs. In the United States, the prevalence of mild to severe OSA (apnea-hypopnea index $\geq 5$ ) was previously estimated to be $26 \%$ in adults. ${ }^{15}$ In a large case-control study of a nationally representative sample of US Medicare beneficiaries, patients not treated for OSA had increased healthcare utilization at all points of service and costs of approximately $\$ 20,000$ in the year before OSA diagnosis compared with matched control patients without sleeprelated breathing disorders. ${ }^{16}$ Although physicians are generally involved in the diagnosis and treatment of OSA, it is well established that both physicians and dentists receive minimal education on the topic of sleep medicine 
in their predoctoral training. In the United States and many other developed countries around the world, the total time spent on sleep education during medical and dental school doctorate programs is approximately 2.5 to 3.5 hours, and approximately $25 \%$ of schools devote no time to sleep education. ${ }^{17-21}$ This minimal sleep education offered to physicians and dentists-in-training globally increased negligibly over the past several decades, from just under 2 hours for physicians in $1993^{18}$ and 30 minutes for dentists reported in 2003. ${ }^{21}$

The effect of minimal hours of education in sleep health is evident by physician self-report of a low level of knowledge of sleep medicine. ${ }^{22}$ Upon completion of medical school, physicians appear to have insufficient education to provide sleep health guidance for their patients, often missing the diagnosis of patients' sleep disorders. ${ }^{23-25}$ Studies indicate readily diagnosable moderate to severe OSA remains undiagnosed in more than $80 \%$ of males and $90 \%$ of females; ${ }^{6,26}$ if mild OSA were included, the percentage of patients in whom OSA was undiagnosed would be substantially higher. In 2016, the American Thoracic Society drew attention to this deficit in training, concluding that PHPs receive little formal education on the importance of sleep to health and on the evaluation and management of common sleep disorders. ${ }^{27}$

From public health and health-cost containment perspectives, there should be additional pathways to diagnosis and management of OSA. Training dentists to identify patients at risk of OSA and manage simple OSA by offering treatment, such as oral appliance therapy (OAT), would serve to expand the PHP workforce who can help meet the public health challenges regarding OSA. ${ }^{2}$ The 2016 Behavioral Risk Factor Surveillance System survey data indicated $69.6 \%$ of the US adult population reported visiting a dentist in the past year. ${ }^{28}$ Because patients see their dentist twice a year or more for preventive dental care, dentists are in a good position to help identify patients with sleep disorders through sleep-focused questions and validated sleep questionnaires. Dentists may also be able to provide OSA preventive strategies in children through orthodontic interventions focused on growth and development of facial and upper airway structures. $^{29}$ When comparing conservative dental interventions to conservative medical interventions for OSA, as many as $81 \%$ of patients preferred dentistprovided oral appliance therapy for OSA to gold standard CPAP treatment. ${ }^{30}$ In clinical trials comparing CPAP with OAT, similarly favorable OSA outcomes were observed, even among patients with moderate to severe OSA. ${ }^{31,32}$ The Mean Disease Alleviation (overall effectiveness) in treating patients with OSA at all severities is a function of treatment efficacy per hour and number of hours of use. ${ }^{33}$ Although greater improvement in apnea-hypopnea index was observed with CPAP, especially in patients with more severe OSA, patients receiving OAT used the device a greater number of hours, resulting in similar treatment effectiveness for other OSA outcomes, such as arterial pressure, sleepiness, and quality of life. ${ }^{31}$

In this study, dentists' and physicians' OSA knowledge was compared using the 18 knowledge items from the Obstructive Sleep Apnea Knowledge and Attitudes (OSAKA) Questionnaire ${ }^{34}$ to determine areas of need for education in these two groups. It was hypothesized that dentists' and physicians' OSA knowledge would not differ significantly. Comparisons were described between dentists' and physicians' knowledge using new data collected from dentists and data from published studies of physicians.

\section{METHODS}

After University of California Los Angeles Institutional Review Board approval, studies of sleepknowledge assessment were conducted using two convenience samples of California dentists under two conditions.

\section{Dentist Survey Studies}

Group 1 participated in an online, cross-sectionalsurvey study, and group 2 participated in a pre-post study of a sleep education intervention; only preintervention data from group 2 participants were analyzed herein. For both dentist groups, the OSAKA Questionnaire items were embedded within a larger survey that included participants' demographic characteristics, other sleep questions, and an item measuring dentists' perceived level of expertise in sleep health using the following response options: 1 (beginner), 2 (novice), 3 (competent), 4 (expert), and 5 (thought leader). This study reports dentists' OSA knowledge using the OSAKA Questionnaire and demographic data collected between January and April 2019.

Two dentist samples were recruited separately. Group 1 participants were recruited through written advertisements in two leading monthly California state dental publications, the California Dental Association (CDA) Journal, and the CDA Update newsletter. Three consecutive monthly advertisements were placed in each publication edition from January through March 2019, encouraging readers to visit a website to take the sleep questionnaire online.

For group 2, advertisements were made through the executive directors of the $32 \mathrm{CDA}$ component member societies. Multiple emails were sent to the executive directors, inviting their members to participate in an educational-intervention research study. Data from the first two CDA components able to schedule the educational intervention were included in this study. Participants in groups 1 and 2 provided informed consent prior to enrollment and data were collected anonymously between January 1 and April 30, 2019. 


\section{Physician Studies}

A review of published studies was conducted that used the OSAKA Questionnaire, ${ }^{34}$ which was published in 2003. The OSAKA was developed for educational needs assessment and evaluation research and has been widely used across multiple physician populations in at least 10 countries around the world. ${ }^{34-45}$ To identify publications of studies reporting on dentists' and physicians' knowledge of OSA using the OSAKA, a search of the literature was conducted using PubMed and Google Scholar using the search terms, "obstructive sleep apnea knowledge and attitudes". Of the 129 papers published through April 30, 2020, a total of 12 unique, peer-reviewed, original research publications (in print or online ahead of print) reporting total OSA-knowledge scores from physician surveys were found. ${ }^{34-45}$ No peer-reviewed, published, dentist survey studies of OSA knowledge using the OSAKA Questionnaire were found. Nine of the 12 publications were eligible for inclusion in analysis of individual items, because scores for each item were published ${ }^{34-42}$ or the authors $^{34-46}$ shared individual-item scores with the first author (personal communication emails: Dr. Navin Devaraj on March 8, 2020; ${ }^{35}$ Dr. Sohan Solanki on March 15, $2020 ;{ }^{36}$ and Dr. Donna Jeffe on April 3, 2020. ${ }^{34}$ Four of the 12 manuscripts also reported results for physician subgroups (eg, by level of training, physician specialties, or geographic location).

\section{OSAKA Questionnaire}

All 18 knowledge items had response options of True, False or Don't Know. Correct responses received 1 point; incorrect and "Don't know" responses and unanswered items were considered "incorrect" and did not receive a point.

\section{Data Analysis}

Differences between physicians' and dentists' knowledge scores (percent correct) for each of the 18 knowledge items and the total OSA knowledge score were examined. For this study, data were combined for all physician groups to compare dentists' and physicians' responses to each knowledge item and total percentagecorrect scores. Based on previously published studies, each item was examined to determine what were considered "gaps" $(<60 \% \text { correct })^{37}$ and "competencies" $(\geq 80 \%$ correct) ${ }^{42}$ as well as to identify disparities between dentists' and physicians' knowledge gaps and competencies. The decision to use $\geq 80 \%$ correct as the cutoff score for competencies in specific OSA knowledge domains was based on otolaryngology residents' comparatively high level of OSA knowledge overall, and that assessment and treatment of patients with OSA are expected competencies for otolaryngology residents in Canada. ${ }^{42}$ Group differences in the total scores and for each of the 18 knowledge items were examined using chisquare tests and were performed using Stata version 15 statistical software (StataCorp, College Station, TX). Bonferroni-adjusted values of $P<.0023$ were considered statistically significant in testing group differences in individual-item and total OSA knowledge scores. The 95\% confidence intervals were calculated for differences in proportions.

\section{RESULTS}

The data were sequentially analyzed as follows. First, the newly collected data from two groups of California dentists were analyzed. Next, the previously published data from physicians were compiled and examined. Finally, the California dentists' data were compared to the physicians' total and individual-item data.

Surveys returned were examined for completeness and only data from dentists who continued the survey past the first half of the OSAKA knowledge items were analyzed. Next, differences in total OSA knowledge scores were tested between dentists in group 1 (107 of 112 online survey) and group 2 pretest (63 of 63 in-person) participants. The two dentist groups did not differ significantly in terms of age, years in practice as a dentist, self-reported expertise, or total OSA knowledge scores (group $1=72.7 \%$ and group $2=75.1 \%$; mean $73.6 \%$ ). Thus, data for the two groups were combined for analysis. Of the 170 dentists included, $74.1 \%$ were general dentists and $58.2 \%$ had received their dental degree from a California dental school. Dentists' average age was 53.6 years (range, 27 to 86 years) and average years in practice was 25.8 years. More than $90 \%$ of participating dentists reported having received $\leq 3$ hours of sleep education during dental school, and more than $70 \%$ reported receiving $\geq 4$ hours of sleep education after graduating from dental school. More than $75 \%$ of participating dentists self-rated their expertise in sleep health at the novice or beginner level (Table 1).

Among the physician studies, surveys were completed in person, by mail, or online. Each study described their criteria for inclusion, and where incomplete surveys were described, the authors reported inclusion of only fully completed surveys in their analysis. The average total OSA knowledge score among all physicians across the 12 published studies $(n=2,559)$ was $63.4 \%$. Four of the 12 studies reported results for subpopulations of physician participants resulting in 19 physician groups. Six of these 19 groups had higher total OSA knowledge scores than the dentist group (Table 2).

Individual-item data were available for 2,041 physicians in 9 studies (Table 3 and Table 4). When comparing dentists with various physician groups' knowledge competencies and gaps for individual 
Table 1. Self-perceived expertise of dentists by hours of post-doctoral education in sleep. ${ }^{a}$

\begin{tabular}{|l|l|l|l|l|l|l|}
\hline $\begin{array}{l}\text { Hours of } \\
\text { education }\end{array}$ & $\begin{array}{l}\text { Total } \\
\mathrm{N}=154^{\mathrm{b}}(\%)\end{array}$ & $\begin{array}{l}\text { Novice } \\
\mathrm{N}=55\end{array}$ & $\begin{array}{l}\text { Beginner } \mathrm{N=63} \\
\mathrm{N}\end{array}$ & $\begin{array}{l}\text { Competent } \\
\mathrm{N}=33\end{array}$ & $\begin{array}{l}\text { Expert } \\
\mathrm{N}=1\end{array}$ & $\begin{array}{l}\text { Thought } \\
\text { Leader } \\
\mathrm{N}=2\end{array}$ \\
\hline 0 & $24(15.6)$ & 18 & 6 & 0 & 0 & 0 \\
\hline $1-3$ & $21(13.6)$ & 16 & 5 & 0 & 0 & 0 \\
\hline $4-9$ & $24(15.6)$ & 11 & 13 & 0 & 0 & 0 \\
\hline $10-24$ & $37(24.0)$ & 7 & 28 & 2 & 0 & 0 \\
\hline $25-64$ & $21(13.6)$ & 2 & 9 & 10 & 0 & 0 \\
\hline $65-99$ & $10(6.5)$ & 1 & 2 & 7 & 0 & 0 \\
\hline $100-250$ & $7(4.6)$ & 0 & 0 & 7 & 0 & 0 \\
\hline $250-1000$ & $8(5.2)$ & 0 & 0 & 6 & 1 & 1 \\
\hline$>1000$ & $2(1.3)$ & 0 & 0 & 1 & 0 & 1 \\
\hline$(\%$ of total $\mathrm{N})$ & $(100)$ & $(35.7)$ & $(40.9)$ & $(21.4)$ & $(0.6)$ & $(1.3)$ \\
\hline
\end{tabular}

a Table adapted from Simmons and Sayre [73], with permission of the Journal of Dental Sleep Medicine. b Sixteen participants did not complete this survey item.

Table 2. Obstructive sleep apnea knowledge total scores on the OSAKAa Questionnaire $^{34}$ for the dentist $(N=170)$ and physician $(N=2,559)$ samples, listed from highest to lowest total scores.

\begin{tabular}{|c|c|c|c|}
\hline Study & Study samples & Total $\mathrm{N}$ & $\begin{array}{l}\text { OSA- } \\
\text { knowledge } \\
\text { total score } \\
(\% \text { correct })\end{array}$ \\
\hline Ansari \& Hu, 2020 [4] & Canadian Otolaryngology residents & 66 & 84.5 \\
\hline Chang et al., 2020 [41] & South African PCPs ${ }^{\mathrm{b}}$ & 41 & 83.6 \\
\hline Schotland \& Jeffe, 2003 [34] & U.S. Internal Medicine physicians & 55 & 79.4 \\
\hline Schotland \& Jeffe, 2003 [34] & U.S. Family Practitioners & 16 & 77.8 \\
\hline Williams et al., 2015 [45] & U.S. community physicians ${ }^{\mathrm{c}}$ & 105 & 77.8 \\
\hline Southwell et al., 2008 [43] & U.S. Cardiologists & 92 & 76.0 \\
\hline Dentist Comparison Group & U.S. (California) Dentists & 170 & 73.6 \\
\hline Chang et al., 2020 [41] & Kenyan PCPs ${ }^{\mathrm{b}}$ & 63 & 67.8 \\
\hline Solanki et al., 2019 [361] & Indian Anesthesiologists & 201 & 66.9 \\
\hline Corso et al., 2017 [39] & Italian Anesthesiologists & 370 & 65.6 \\
\hline Cherrez Ojeda et al., 2013 [40] & Peruvian $\mathrm{PCPs}^{\mathrm{b}}$ & 93 & 65.4 \\
\hline Devaraj, 2020 [35] & Malaysian PCPs ${ }^{b}$ & 207 & 64.4 \\
\hline Schotland \& Jeffe, 2003 [34] & U.S. Pediatricians & 37 & 62.8 \\
\hline Wang et al., 2011 [44] & Chinese Anesthesiologists & 321 & 62.3 \\
\hline Cherrez Ojeda et al., 2013 [40] & Venezuelan PCPs ${ }^{\mathrm{b}}$ & 85 & 61.2 \\
\hline Chang et al., 2020 [42] & Nigerian $\mathrm{PCPs}^{\dagger}$ & 80 & 61.1 \\
\hline Ozoh et al., 2017 [39] & Nigerian Internal Medicine residents & 235 & 59.8 \\
\hline Ozoh et al., 2017 [39] & Nigerian PCPs ${ }^{\mathrm{b}}$ & 38 & 55.7 \\
\hline Cherrez Ojeda et al.2013 [40] & Ecuadorian PCPs $^{\mathrm{b}}$ & 189 & 54.3 \\
\hline Chérrez-Ojeda et al.2018 [37] & Ecuadorian recent medical graduates & 265 & 53.5 \\
\hline
\end{tabular}


Table 3. Obstructive sleep apnea knowledge competencies and gaps in response to individual items on the OSAKA Questionnaire ${ }^{34}$ ordered by greatest number of questions answered correctly by $\geq 80 \%$ of participants (Competencies).

\begin{tabular}{|c|c|c|c|c|}
\hline Study & $\begin{array}{l}\text { Study samples and (OSAKA mean total } \\
\text { score) }\end{array}$ & Total $\mathrm{N}^{\mathrm{a}}$ & $\begin{array}{c}\text { Items answered } \\
\text { correctly by } \geq 80 \% \text { of } \\
\text { participants } \\
\text { (Competencies) }\end{array}$ & $\begin{array}{c}\text { Items answered } \\
\text { correctly by }<60 \% \text { of } \\
\text { participants } \\
(\mathrm{Gaps})\end{array}$ \\
\hline Ansari \& $\mathrm{Hu}, 2020$ [42] & Canadian Otolaryngology residents $\quad$ (84.5) & 66 & 15 & 3 \\
\hline Chang et al., $2020[41]$ & South African PCPs & 41 & 13 & 2 \\
\hline Schotland \& Jeffe, 2003 [34] & U.S. Internal Medicine physicians & 55 & 10 & 1 \\
\hline Schotland \& Jeffe, 2003 [34] & U.S. Family Practitioners & 16 & 9 & 2 \\
\hline Dentist Comparison Group & U.S. (California) Dentists & 170 & 9 & 4 \\
\hline Corso et al., 2017 [38] & Italian Anesthesiologists & 370 & 9 & 6 \\
\hline Devaraj, 2020 [35] & Malaysian PCPs & 207 & 7 & 6 \\
\hline Cherrez Ojeda et al., 2013 [40] & Peruvian PCPs & 93 & 7 & 7 \\
\hline Schotland \& Jeffe, 2003 [34] & U.S. Pediatricians & 37 & 7 & 7 \\
\hline Solanki et al., 2019 [36] & Indian Anesthesiologists & 201 & 6 & 6 \\
\hline Chang et al., $2020[41]$ & Kenyan PCPs & 63 & 6 & 7 \\
\hline Ozoh et al., 2017 [39] & Nigerian Internal Medicine residents (59.8) & 235 & 6 & 8 \\
\hline Cherrez Ojeda et al., 2013 [40] & Venezuelan PCP & 85 & 6 & 8 \\
\hline Chang et al., 2020 [41] & Nigerian PCPs & 80 & 5 & 9 \\
\hline Ozoh et al., 2017 [39] & Nigerian PCPs & 38 & 4 & 9 \\
\hline Cherrez Ojeda et al., 2013 [40] & Ecuadorian PCPs & 189 & 4 & 11 \\
\hline Chérrez-Ojeda et al., 2018 [37] & Ecuadorian recent medical graduates (53.5) & 265 & 2 & 10 \\
\hline
\end{tabular}

OSA = obstructive sleep apnea; ${ }^{\dagger}$ OSAKA = Obstructive Sleep Apnea Knowledge and Attitudes; PCPs = primary care physicians.

a In all, 2,559 physicians and 170 dentists had total scores; of the 2,559 physicians, 2,041 had data for individual knowledge items. ${ }^{b}$ Community physicians PCPs and various specialties and practicing in a large metropolitan area. 
Table 4. Number of published studies, sample subgroups, and participants for which total and individual-item obstructive sleep apnea knowledge scores were reported using the OSAKA Questionnaire. ${ }^{34}$

\begin{tabular}{|c|c|c|c|c|c|c|c|c|}
\hline & \multicolumn{2}{|c|}{ All Physicians } & \multicolumn{2}{|c|}{$\begin{array}{l}\text { Non-US } \\
\text { Physicians }\end{array}$} & \multicolumn{2}{|c|}{$\begin{array}{l}\text { Canadian } \\
\text { Otolaryngology } \\
\text { Residents }\end{array}$} & \multicolumn{2}{|c|}{ US Physicians } \\
\hline & $\begin{array}{l}\text { Total } \\
\text { score } \\
\mathrm{N}\end{array}$ & $\begin{array}{l}\text { Item } \\
\text { scores } \\
\mathrm{N}\end{array}$ & $\begin{array}{l}\text { Total } \\
\text { score } \\
\mathrm{N} \\
\end{array}$ & $\begin{array}{l}\text { Item } \\
\text { scores } \\
\mathrm{N}\end{array}$ & $\begin{array}{l}\text { Total } \\
\text { score } \\
\mathrm{N}\end{array}$ & $\begin{array}{l}\text { Item } \\
\text { scores } \\
\mathrm{N}\end{array}$ & $\begin{array}{l}\text { Total } \\
\text { score } \\
\mathrm{N}\end{array}$ & $\begin{array}{l}\text { Item } \\
\text { scores } \\
\mathrm{N}\end{array}$ \\
\hline No. of studies & 12 & 9 & 8 & 7 & 1 & 1 & 3 & 1 \\
\hline No. of sub-groups & 20 & 16 & 13 & 12 & 0 & 0 & 5 & 3 \\
\hline No. of participants & 2,559 & 2,041 & 2,188 & 1,867 & 66 & 66 & 305 & 108 \\
\hline
\end{tabular}

OSA = obstructive sleep apnea; OSAKA = Obstructive Sleep Apnea Knowledge and Attitudes. a Excludes Canadian otolaryngology residents.

knowledge items, 3 of the 16 physician groups with individual-item data showed greater knowledge competencies, and 4 of 16 physician groups showed fewer knowledge gaps than the dentists (Table 3). Dentists and the combined group of all physicians had knowledge gaps ( $<60 \%$ answered items correctly) in the same four items, but the all-physician group had gaps in two more items (Table 5). OSA knowledge gaps over the 18 items were greater in number among other non-US physicians than among dentists, US physicians, and Canadian otolaryngology residents. Notably, the otolaryngology resident group scored $\geq 80 \%$ correct on all but three items, and this was the only group with a statistically significant higher total knowledge score than dentists (Table 5). When comparing dentists with various groups of physicians among all published studies of physicians reporting total OSA knowledge scores, dentists scored significantly higher than the non-US physician group and the physician group overall, but the otolaryngology residents had significantly higher OSA knowledge scores than each of the other groups (Table 6).

\section{DISCUSSION}

This study showed that US dentists' OSA knowledge using the OSAKA Questionnaire ${ }^{34}$ was noninferior to OSA knowledge among physicians in the United States and other countries, except when compared with Canadian otolaryngology residents. Specific gaps in knowledge were mostly consistent between dentists and all physicians combined, although physicians overall had more knowledge gaps. The number of postdoctoral hours of sleep medicine education received by physicians in the current study is unknown; however, almost one-third of dentists in the current study sample reported receiving at least 25 hours of postdoctoral education in sleep health. OSA knowledge scores were higher among otolaryngology residents and dentists compared with other physicians, which would be expected given the scope of their training, routine practice, and focused attention on addressing pathologies in this anatomic region. Although it was not specified in the reviewed publication how much sleep medicine training otolaryngology residents had received, more than $80 \%$ of them had already completed more than 1 year of residency training at the time they completed the OSAKA, and more than $45 \%$ had 3 or more years of training. ${ }^{42}$

A 2008 US national survey of practicing general dentists $(n=1,945)$ found that most respondents thought it was important for dentists to screen for HIV, hepatitis, diabetes, cardiovascular disease, and hypertension. These respondents were willing to conduct tests that yield immediate results and refer patients for medical follow-up as indicated. ${ }^{46}$ Dentists are increasingly involved in addressing public health issues not specifically related to tooth damage and periodontal disease, such as screening for cancer, ${ }^{47,48}$ hypertension and cardiovascular health, ${ }^{49}$ diabetes,${ }^{50}$ nicotine addiction, ${ }^{51-54}$ and obesity. .556

Sleep disorders, in particular, are being screened for and addressed by dentists. In Finland, a survey of dentists' knowledge and practice regarding OSA treatment and referrals suggested that dentists could play an important role in identifying and treating sleep disorders, but more education was needed. ${ }^{57} \mathrm{~A}$ nationwide, cross-sectional study of Lithuanian dentists' OSA knowledge concluded that additional education and implementation strategies should be considered in order to overcome barriers to identifying and treating sleep disorders. ${ }^{58}$ In the United States, many general dentists reported that they screen for OSA by interview, identifying OSA-associated anatomic parameters, using a sleep questionnaire or ordering a home sleep apnea test. ${ }^{59}$

Although the experiences of physicians outside the United States may not be comparable to the experiences of 
Table 5. Mean scores (percentage correct) for individual obstructive sleep apnea knowledge items using the OSAKA Questionnaire. ${ }^{34}$

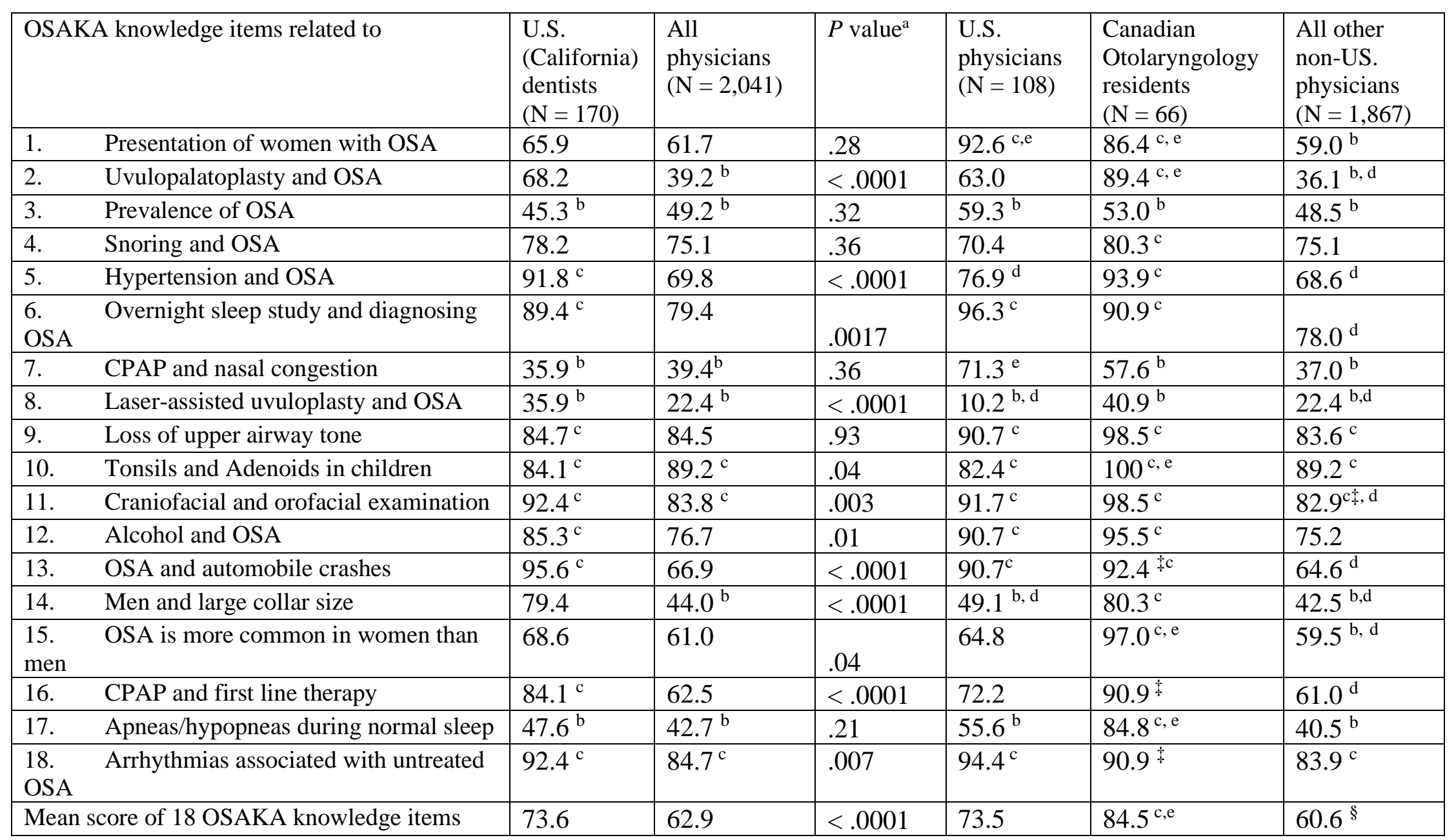

CPAP = continuous positive airway pressure OSA = obstructive sleep apnea; OSAKA = Obstructive Sleep Apnea Knowledge and Attitudes ${ }^{a}$ Chi-square tests comparing all dentists with all physicians; Bonferroni adjusted $P<.0023$ considered significant.

b Scores $<60 \%$ correct indicate an OSA-knowledge gap for that item for that group.

c Scores $\geq 80 \%$ correct indicate an OSA-knowledge competency for that item for that group.

dDentists scored significantly higher than this physician group on this item.

e Physicians in this group scored significantly higher than dentists on this item. 
Table 6. Total knowledge scores on the OSAKA Questionnaire ${ }^{34}$ listed from highest to lowest score, including dentists and all published studies of physicians reporting total scores, by sample group.

\begin{tabular}{|l|l|l|}
\hline Group & Sample N & $\begin{array}{l}\text { Total OSAKA score } \\
\text { (\% correct) }\end{array}$ \\
\hline Canadian Otolaryngology residents & 66 & 84.5 \\
\hline US Physicians & 305 & 75.6 \\
\hline US. (California) Dentists & 170 & 73.6 \\
\hline All physicians & 2,454 & 63.3 \\
\hline Non-US physicians, excluding otolaryngologists & 2,188 & 61.5 \\
\hline
\end{tabular}

OSAKA = Obstructive Sleep Apnea Knowledge and Attitudes

the US physicians, both US and non-US physician groups receive minimal sleep education (187 minutes in the US programs and 146 minutes in the international physician programs). ${ }^{17}$ Overall, the inadequate amount (approximately 3 hours) of formal education in sleep health and sleep disorders such as OSA in dental and medical schools does little to prepare these PHPs to identify, diagnose, and manage OSA. This burdens the far smaller numbers of sleep medicine specialists and otolaryngologists with more patients than they can manage, leading to delays in treatment and lack of triage in addressing the complicated cases requiring urgent specialist care.

There is a dearth of sleep physicians in the United States, according to a recent report from the 2018 American Academy of Sleep Medicine President, Dr. Ilene Rosen, largely due to the attrition rate of retiring sleep physicians from the workforce, which far exceeds the slow uptake of physicians seeking to replace them. ${ }^{60}$ This speaks to an increasing gap in addressing the public health problem of OSA, especially with already low rates of recognition of sleep disorders in primary care. ${ }^{24}$ There is an immediate need to increase capacity of the PHP workforce, including dentists, to be able to diagnose and manage noncomplicated OSA and to refer complicated cases to sleep specialists.

There is a continuum from non-OSA snoring to simple OSA to complicated OSA with comorbidities that can be life threatening. If an individual with OSA has no medical illness, no unmanaged sleepiness or other sleep health issues, they could be considered a simple case of OSA. Using a stepped-care model, simple OSA cases and nonOSA snoring (absent comorbidities or with comorbidities that are well managed and not progressive) could be managed by PHPs, such as PCPs and dentists. Complicated OSA management speaks to the need for a collaborativecare model between PCPs or dentists and other medical specialists, such as sleep physicians and otolaryngologists.
Increasing the number of PHPs, including PCPs and dentists, who can screen for and/or manage noncomplicated OSA as well as refer more complicated cases to sleep specialists, can improve sleep health outcomes at the population level. There is evidence that lower socioeconomic status is associated with an increased risk of OSA in working-age adults, children, and adolescents; in addition, older adults and patients with low socioeconomic status are less likely to receive OSA treatment. ${ }^{61-63}$ With a greater number of providers able to screen and manage OSA, the $\operatorname{cost}^{16}$ and other access-tocare barriers, such as geographical barriers, are likely to be reduced. Some evidence indicates that care provided by non-sleep specialists and sleep specialists may yield similar outcomes using therapies such as CPAP. ${ }^{64,65}$ Finally, the rationale to use CPAP therapy to improve cardiovascular disease outcomes, even in patients with severe OSA, has come into question. ${ }^{66}$ The controversy is moving in the direction of treating those patients with excessive daytime sleepiness, because increased risk of cardiovascular events was found to occur almost exclusively in patients with OSA who report excessive sleepiness. ${ }^{10-13,67,68}$

Suggestions to improve the capacity of sleep health providers to identify and treat patients with OSA include (1) increasing the minimum amount of sleep health education during dental and medical school to between 10 to 24 hours, noting that 35 of 37 dentists who reported 10 to 24 hours of postdoctoral sleep education considered their sleep health expertise at the novice or beginner level (Table 1); (2) increasing opportunities for sleep externships, crossdisciplinary postdoctoral programs, and credentialing; (3) establishing a more evolved stepped-care model for sleep health and sleep disorders to match population-level problems utilizing available resources such as PHPs; and (4) improving the public health footprint to address sleep problems, such as reducing social inequalities associated with OSA and other sleep health problems, in addition to addressing the expanded public sleep health initiatives in the Healthy People 2030 sleep goals. ${ }^{69}$ 
There are several limitations to this study. A single OSA-focused questionnaire, although validated, may not adequately test OSA knowledge. The various crosssectional studies of convenience samples included in this study were conducted over 17 years and included physicians around the world, in various specialties and at different stages of training and practice. Because all studies collected cross-sectional data, whether OSA-knowledge has increased or decreased over time could not be determined. There is some indication that knowledge of OSA has not significantly increased in physician groups in that the number of hours of sleep education during medical school has not changed since $1993^{17,18}$ and the two groups of PCPs tested using the OSAKA in $2003^{34}$ and $2015^{45}$ had similar total OSAKA knowledge scores. Although physicians represented 11 countries, all physician and dentist participants were self-selected, perhaps based on their interest in sleep health and sleep disorders, and all dentists practiced in California. Moreover, because the online survey of dentists was conducted anonymously, it could not be determined whether any dentists participated in both studies. It is expected that compared with the study sample, other dentists with a university masters or other advanced degree(s) in sleep medicine, oral surgeons, recent orofacial pain/sleep residency graduates, ${ }^{70}$ and dentists credentialed by the American Board of Dental Sleep Medicine, European Sleep Research Society or World Sleep Society would be more knowledgeable about OSA. The low response to the online survey (dentist group 1) is also a study limitation, although expected, because interested participants were required to find and complete the online survey. In addition, only 2 of 32 CDA component member societies participated in the educational intervention study due to time and financial constraints. Thus, both physician and dentist participants' results are not generalizable to the population of all physicians and dentists.

\section{CONCLUSIONS}

There is a general lack of education about sleep and OSA offered to both physicians and dentists during their doctorate training. A concerted effort to increase the negligible amount of OSA education for medical and dental students ${ }^{17,21}$ is required to address and improve OSA problems at the population level. Dentists in this study had noninferior knowledge of OSA compared to most other physician samples. With just over 200,000 dentists in the United States in 2019, ${ }^{71}$ dentists are a large group of PHPs who can help to screen, diagnose, and potentially treat patients presenting with OSA, as governed by each state's dental licensing laws and accreditation boards, or refer them to sleep or other specialists as needed. Expanding the role for dentists in the diagnosis and potential management of OSA and expanding the number of dental healthcare facilities as portals of entry into OSA care can help promote sustainable, favorable sleep health outcomes at the population level. Educating and broadly supporting dentists in this role will help improve the lives of patients and reduce the escalated healthcare costs associated with untreated OSA. ${ }^{7,16,72}$

\section{ABBREVIATIONS}

CDA - California Dental Association

CPAP - continuous positive airway pressure

OSA - obstructive sleep apnea

OSAKA - Obstructive Sleep Apnea Knowledge and Attitudes

PCP - primary care physician

PHP - primary healthcare provider

\section{ACKNOWLEDGMENTS}

The authors would like to thank Cathy Lang, $\mathrm{PhD}$, $\mathrm{MPH}$, who advised the first author during development of the study design and reviewed an early draft of this manuscript.

\section{REFERENCES}

1. Institute of Medicine. Sleep Disorders and Sleep Deprivation: An Unmet Public Health Problem. Colten HR, Altevogt BM, editors. Washington, DC: National Academies Press, 2006 https://doi.org/10.17226/11617.

2. US Department of Health and Human Services. Office of Disease Prevention and Health Promotion. Healthy People 2020. Sleep Health. Available at: https://www.healthypeople.gov/2020/topicsobjectives/topic/sleep-health. Accessed May 24, 2021.

3. Kato M, Adachi T, Koshino Y, Somers VK. Obstructive sleep apnea and cardiovascular disease. Circ J. 2009 Aug;73(8):1363-70. doi: 10.1253/circj.cj-09-0364.

4. Young T. Rationale, design, and findings from the Wisconsin Sleep Cohort Study: Toward understanding the total societal burden of sleep disordered breathing. Sleep Medicine Clinics. 2009;4(1):37-46. DOI: 10.1016/j.jsmc.2008.11.003.

5. Leinum CJ, Dopp JM, Morgan BJ. Sleep-disordered breathing and obesity: Pathophysiology, complications, and treatment. Nutr Clin Pract. 2009 Dec;24(6):675-87. doi: 10.1177/0884533609351532.

6. Young T, Evans L, Finn L, Palta M. Estimation of the clinically diagnosed proportion of sleep apnea syndrome in middle-aged men and women. Sleep. 1997;20(9):705-706. doi: 10.1093/sleep/20.9.705.

7. American Academy of Sleep Medicine. Hidden health crisis costing America billions: Underdiagnosing and undertreating obstructive sleep apnea draining healthcare system. Mountain View, CA: Frost \& Sullivan. 2016. Available at: https://j2vjt3dnbra3ps71l1clb4q2wpengine.netdna-ssl.com/wp-content/uploads/2017/10/sleep-apneaeconomic-crisis.pdf. Accessed January 4, 2021

8. Epstein LJ, Kristo D, Strollo PJ, et al. Clinical guideline for the evaluation, management and long-term care of obstructive sleep apnea in adults. J Clin Sleep Med 2009;5(3):263-276. [Erratum. J Clin Sleep Med. 2010;6(3):np.]

9. Rotenberg BW, Murariu D, Pang KP. Trends in CPAP adherence over twenty years of data collection: a flattened curve. J Otolaryngol Head Neck Surg. 2016;45(1):43. doi:10.1186/s40463-016-0156-0.

Barbé F, Mayoralas LR, Duran J, et al. Treatment with continuous 
positive airway pressure is not effective in patients with sleep apnea but no daytime sleepiness. a randomized, controlled trial. Ann Intern Med. 2001;134(11):1015-1023. doi: 10.7326/0003-4819-134-11200106050-00007. PMID: 11388814.

11. Robinson GV, Smith DM, Langford BA, Davies RJ, Stradling JR. Continuous positive airway pressure does not reduce blood pressure in nonsleepy hypertensive OSA patients. Eur Respir $J$. 2006;27(6):1229-35. doi: 10.1183/09031936.06.00062805. Epub 2006 Feb 2. PMID: 16455835.

12. Barbé F, Durán-Cantolla J, Sánchez-de-la-Torre M, et al; Spanish Sleep And Breathing Network. Effect of continuous positive airway pressure on the incidence of hypertension and cardiovascular events in nonsleepy patients with obstructive sleep apnea: a randomized controlled trial. JAMA. 2012;307(20):2161-2166. doi: 10.1001/jama.2012.4366. PMID: 22618923.

13. Peker Y, Glantz H, Eulenburg C, Wegscheider K, Herlitz J, Thunström E. Effect of positive airway pressure on cardiovascular outcomes in coronary artery disease patients with nonsleepy obstructive sleep apnea. The RICCADSA Randomized Controlled Trial. Am J Respir Crit Care Med. 2016;194(5):613-620. doi: 10.1164/rccm.201601-0088OC. PMID: 26914592.

14. Benjafield AV, Ayas NT, Eastwood PR et al. Estimation of the global prevalence and burden of obstructive sleep apnoea: a literature-based analysis. Lancet Respir Med. 2019;(8):687-698. doi: 10.1016/S22132600(19)30198-5.

15. Peppard PE, Young T, Barnet JH, Palta M, Hagen EW, Hla KM. Increased prevalence of sleep-disordered breathing in adults. Am J Epidemiol. 2013;177(9):1006-1014. doi: 10.1093/aje/kws342. PMID: 23589584; PMCID: PMC3639722.

16. Wickwire EM, Tom SE, Vadlamani A, et al. Older adult US Medicare beneficiaries with untreated obstructive sleep apnea are heavier users of health care than matched control patients. J Clin Sleep Med. 2020 Jan 15;16(1):81-89. doi: 10.5664/jcsm.8128

17. Mindell JA, Bartle A, Wahab NA, et al. Sleep education in medical school curriculum: a glimpse across countries. Sleep Med. 2011;12(9):928-931. doi:10.1016/j.sleep.2011.07.001

18. Rosen RC, Rosekind M, Rosevear C, Cole WE, Dement WC. Physician education in sleep and sleep disorders: a national survey of U.S. medical schools. Sleep. 1993;16(3):249-254. doi: 10.1093/sleep/16.3.249.

19. Simmons MS, Pullinger A. Education in sleep disorders in US dental schools DDS programs. Sleep Breath. 2012;16(2):383-392. doi:10.1007/s11325-011-0507-z

20. Balasubramaniam R, Pullinger, A, Simmons, M. Sleep medicine education at dental schools in Australia and New Zealand. J Am Acad Dent Sleep Med. 2014;1(1):9-16.

21. Ivanhoe JR, Frazier KB, Parr GR, Haywood VB. The teaching and treatment of upper airway sleep disorders in North American dental schools. J Prosthet Dent. 2003;89(3):292-296. doi: 10.1067/mpr.2003.52.

22. Saleem AH, Al Rashed FA, Alkharboush GA, et al. Primary care physicians' knowledge of sleep medicine and barriers to transfer of patients with sleep disorders. Saudi Med J. 2017;38(5):553-559. doi: $10.15537 / \mathrm{smj} .2017 .5 .17936$

23. Papp KK, Penrod CE, Strohl KP. Knowledge and attitudes of primary care physicians toward sleep and sleep disorders. Sleep Breath. 2002;6(3):103-109. doi:10.1007/s11325-002-0103-3

24. Purim KSM, Guimarães ATB, Titski ACK, Leite N. Sleep deprivation and drowsiness of medical residents and medical students. Rev Col Bras Cir. 2016;43(6):438-444. doi:10.1590/0100-69912016006005

25. Rosen RC, Zozula R, Jahn EG, Carson JL. Low rates of recognition of sleep disorders in primary care: comparison of a community-based versus clinical academic setting. Sleep Med. 2001;2(1):47-55. doi:10.1016/S1389-9457(00)00043-5

26. Watson NF. Health care savings: The economic value of diagnostic and therapeutic care for obstructive sleep apnea. J Clin Sleep Med.
2016;12(8):1075-1077. doi:10.5664/jc

27. Mukherjee S, Patel SR, Kales SN, et al. An Official American Thoracic Society Statement: The Importance of Healthy Sleep. Recommendations and Future Priorities. Am J Respir Crit Care Med. 2015;191(12):1450-1458. doi:10.1164/rccm.201504-0767ST

28. Lutfiyya MN, Gross AJ, Soffe B, Lipsky MS. Dental care utilization: examining the associations between health services deficits and not having a dental visit in past 12 months. BMC Public Health. 2019;19(1):265. Published 2019 Mar 5. doi:10.1186/s12889-0196590-y

29. Verma SK, Maheshwari S, Sharma NK, Prabhat KC. Role of oral health professional in pediatric obstructive sleep apnea. Natl $J$ Maxillofac Surg. 2010;1(1):35-40. doi: 10.4103/0975-5950.69162.

30. Tan YK, L'Estrange PR, Luo YM, et al. Mandibular advancement splints and continuous positive airway pressure in patients with obstructive sleep apnoea: a randomized cross-over trial. Eur J Orthod. 2002;24(3):239-249. doi:10.1093/ejo/24.3.239

31. Phillips CL, Grunstein RR, Darendeliler MA, et al. Health outcomes of continuous positive airway pressure versus oral appliance treatment for obstructive sleep apnea: a randomized controlled trial. Am J Respir Crit Care Med. 2013;187(8):879-87. doi: 10.1164/rccm.201212$2223 \mathrm{OC}$

32. Doff MH, Hoekema A, Wijkstra PJ, et al. Oral appliance versus continuous positive airway pressure in obstructive sleep apnea syndrome: a 2-year follow-up. Sleep. 2013;36(9):1289-96. doi: $10.5665 /$ sleep. 2948 .

33. Vanderveken OM, Dieltjens M, Wouters K, De Backer WA, Van de Heyning PH, Braerm MJ. Objective measurement of compliance during oral appliance therapy for sleep-disordered breathing. Thorax 2013;68:91-96. doi: 10.1136/thoraxjnl-2012-201900.

34. Schotland HM, Jeffe DB. Development of the Obstructive Sleep Apnea Knowledge and Attitudes (OSAKA) Questionnaire. Sleep Med. 2003;4(5):443-450. doi:10.1016/S1389-9457(03)00073-X [Erratum published Sleep Med. 2008;9:705.]

35. Devaraj NK. Knowledge, attitude, and practice regarding obstructive sleep apnea among primary care physicians. Sleep Breath. $2020 \mathrm{Feb}$ 24. doi: 10.1007/s11325-020-02040-1.

36. Solanki SL, Karan N, Parab SY. Obstructive sleep apnoea and its knowledge and attitude among Indian anaesthesiolgists - A survey study. Indian J Anaesth. 2019;63(8):648-652. doi: 10.4103/ija.IJA183-19.

37. Chérrez-Ojeda I, Calderón JC, Fernández García A, et al. Obstructive sleep apnea knowledge and attitudes among recent medical graduates training in Ecuador. Multidiscip Respir Med. 2018;13:5. doi: 10.1186/s40248-018-0117-8. eCollection 2018.

38. Corso RM, Sorbello M, Buccioli M, et al. Survey of knowledge and attitudes about obstructive sleep apnoea among Italian anaesthetists. Turk J Anaesthesiol Reanim. 2017;45(3):146-152. doi: 10.5152/TJAR.2017.51423.

39. Ozoh OB, Ojo OO, Iwuala SO, Akinkugb AO, Desalu OO, Okubadejo $\mathrm{NU}$. Is the knowledge and attitude of physicians in Nigeria adequate for the diagnosis and management of obstructive sleep apnea? Sleep Breath. 2017;21(2):521-527. doi: 10.1007/s11325-016-1407-z.

40. Cherrez Ojeda I, Jeffe DB, Guerrero T, et al. Attitudes and knowledge about obstructive sleep apnea among Latin American primary care physicians. Sleep Med. 2013;14(10):973-7. doi: 10.1016/j.sleep.2013.06.005.

41. Chang JR, Akemokwe FM, Marangu DM, et al. Obstructive sleep apnea awareness among primary care physicians in Africa. Ann Am Thorac Soc. 2020;17(1):98-106. doi:10.1513/AnnalsATS.201903$218 \mathrm{OC}$

42. Ansari S, Hu A. Knowledge and confidence in managing obstructive sleep apnea patients in Canadian otolaryngology - head and neck surgery residents: a cross sectional survey. J Otolaryngol Head Neck Surg. 2020;49(1):21. doi: 10.1186/s40463-020-00417-6.

43. Southwell C, Moallem M, Auckley D. Cardiologist's knowledge and 
attitudes about obstructive sleep apnea: a survey study. Sleep Breath. 2008;12(4):295-302. doi: 10.1007/s11325-008-0170-1.

Wang CL, Li XZ, Cai XL, Pan XL, Min J. Anesthesiologists's knowledge and attitudes about obstructive sleep apnea: a survey study. Sleep Breath. 2012;16(1):41-46. doi: 10.1007/s11325-0110482-4.

45. Williams NJ, Nunes JV, Zizi F, et al. Factors associated with referrals for obstructive sleep apnea evaluation among community physicians. J Clin Sleep Med. 2015;11(1):23-26. doi: 10.5664/jcsm.4356.

46. Greenberg BL, Glick M, Frantsve-Hawley J, Kantor ML. Dentists' attitudes toward chairside screening for medical conditions. J Am Dent Assoc. 2010;141(1):52-62. doi: 10.14219/jada.archive.2010.0021.

47. Aldossri M, Okoronkwo C, Dodd V, Manson H, Singhal S. Dentists' capacity to mitigate the burden of oral cancers in Ontario, Canada. J Can Dent Assoc. 2020 Feb;86:k2.

48. Field, E., Field, J. Lung cancer: a potential role for dentists. Br Dent J. 2020;228:413-414. https://doi.org/10.1038/s41415-020-1418-9

49. Carramolino-Cuéllar E, Tomás I, Jiménez-Soriano Y. Relationship between the oral cavity and cardiovascular diseases and metabolic syndrome. Med Oral Patol Oral Cir Bucal. 2014;19(3):e289-294. doi: 10.4317/medoral.19563.

50. Lalla E, Kunzel C, Burkett S, Cheng B, Lamster IB. Identification of unrecognized diabetes and pre-diabetes in a dental setting. J Dent Res. 2011;90(7):855-860. doi:10.1177/0022034511407069

51. Jannat-Khah DP, McNeely J, Pereyra MR, et al. Dentists' selfperceived role in offering tobacco cessation services: results from a nationally representative survey, United States, 2010-2011. Prev Chronic Dis. 2014;11:E196. doi:10.5888/pcd11.140186

52. Albert D, Ward A. Tobacco cessation in the dental office. Dent Clin North Am. 2012;56(4):747-770. doi:10.1016/j.cden.2012.07.004

53. Stacey F, Heasman PA, Heasman L, Hepburn S, McCracken GI, Preshaw PM. Smoking cessation as a dental intervention--views of the profession. Br Dent J. 2006;201(2):109-113; discussion 99. doi:10.1038/sj.bdj.4813847

54. Yusuf H, Kolliakou A, Ntouva A, et al. Predictors of dentists' behaviours in delivering prevention in primary dental care in England: using the theory of planned behaviour. BMC Health Serv Res. 2016;16:44. doi:10.1186/s12913-016-1293-x

55. Greenberg BL, Glick M, Tavares M. Addressing obesity in the dental setting: What can be learned from oral health care professionals' efforts to screen for medical conditions. J Public Health Dent. 2017;77 Suppl 1:S67-S78. doi:10.1111/jphd.12223

56. Gomes FJS, Paula ABP, Curran AE, Rodrigues MA, Ferreira MM, Palmeirão Carrilho EV. Portuguese Dentists' Attitudes Towards Their Role in Addressing Obesity. Oral Health Prev Dent. 2016;14(1):1320. doi:10.3290/j.ohpd.a34050

57. Vuorjoki-Ranta T-R, Lobbezoo F, Vehkalahti M, Tuomilehto H. Treatment of obstructive sleep apnoea patients in community dental care: knowledge and attitudes among general dental practitioners and specialist dentists. J Oral Rehabil. 2016;43(12):937-942. doi:10.1111/joor.12441

58. Jokubauskas L, Pileičikienè G, Žekonis G, Baltrušaitytė A. Lithuanian dentists' knowledge, attitudes, and clinical practices regarding obstructive sleep apnea: A nationwide cross-sectional study. Cranio. 2018:1-8. doi:10.1080/08869634.2018.1437006

59. Chiang HK, Long A, Carrico CK, Robinson R. The prevalence of general dentists who screen for obstructive sleep apnea. J Dent Sleep Med. 2018;5(3):55-60. doi: 10.3390/ijerph17228460.

60. Rosen IM. Report of the 2017-2018 AASM President. Available at: https://aasm.org/resources/pdf/rosen-president-report-2017.pdf. Accessed May 24, 2021.

61. Etindele Sosso FA, Matos E. Socioeconomic disparities in obstructive sleep apnea: a systematic review of empirical research. Sleep Breath. 2021 Jan 16. doi: 10.1007/s11325-020-02274-z. PMID: 33452999.
Fleury M, Le Vaillant M, Pelletier-Fleury N; IRSR sleep cohort group. Socio-economic status: A barrier to access to mandibular advancement device therapy for patients with obstructive sleep apnea syndrome in France. PLoS One. 2015;10(9):e0138689. doi: 10.1371/journal.pone.0138689. PMID: 26402443; PMCID: PMC4581831.

63. Braley TJ, Dunietz GL, Chervin RD, Lisabeth LD, Skolarus LE, Burke JF. Recognition and diagnosis of obstructive sleep apnea in older Americans. J Am Geriatr Soc. 2018;66(7):1296-1302.

64. Kunisaki KM, Greer N, Khalil W, et al. Provider types and outcomes in obstructive sleep apnea case finding and treatment: a systematic review. Ann Intern Med. 2018;168(3):195-202. doi: 10.7326/M172511. PMID: 29379962.

65. Kunisaki KM, Khalil W, Koffel E, et al. The comparative effectiveness, harms, and cost of care models for the evaluation and treatment of obstructive sleep apnea (OSA): A Systematic Review. Washington, DC, Department of Veterans Affairs, July 18, 2017. PMID: $28715166 . \quad$ Available at: https://europepmc.org/article/MED/28715166/NBK441788\#freefull-text. Accessed May 28, 2021.

66. McEvoy RD, Antic NA, Heeley E, et al; for the SAVE Investigators and Coordinators. CPAP for prevention of cardiovascular events in obstructive sleep apnea. N Engl J Med. 2016;375(10):919-931. doi: 10.1056/NEJMoa1606599. PMID: 27571048.

67. Mazzotti DR, Keenan BT, Lim DC, Gottlieb DJ, Kim J, Pack AI. Symptom subtypes of obstructive sleep apnea predict incidence of cardiovascular outcomes. Am J Respir Crit Care Med. 2019;200(4):493-506. doi: 10.1164/rccm.201808-1509OC. PMID: 30764637; PMCID: PMC6701040,

68. Javaheri S., Martinez-Garcia M.A. Campos-Rodriguez F. CPAP treatment and cardiovascular prevention: we need to change the design and implementation of our trials. Chest. 2019;156:431-437.

69. U.S. Department of Health and Human Services. Office of Disease Prevention and Health Promotion. Healthy People 2030. Sleep. Available at: https://health.gov/healthypeople/objectives-anddata/browse-objectives/sleep. Accessed May 24, 2021.

70. Moreno-Hay I, Hernández I, Mulet M, et al. Sleep medicine education in US and Canadian orofacial pain residency programs: Survey outcomes. J Am Dent Assoc. 2020;151(12):962-968. doi: 10.1016/j.aime.2020.04.022.

71. American Dental Association. Health Policy Institute. Supply and Profile of Dentists: Supply of Dentists in the U.S.: 2001-2019, February 2020. Available at: https://www.ada.org/en/scienceresearch/health-policy-institute/data-center/supply-and-profile-ofdentists. Accessed May 24, 2021.

72. Sharples L, Glover M, Clutterbuck-James A, et al. Clinical effectiveness and cost-effectiveness results from the randomised controlled Trial of Oral Mandibular Advancement Devices for Obstructive sleep apnoea-hypopnoea (TOMADO) and long-term economic analysis of oral devices and continuous positive airway pressure. Health Technol Assess. 2014;18.

73. Simmons M, Sayre J. Testing dentists' general sleep knowledge with the ASKME survey. J Dent Sleep Med. 2020;7(4). Available at: https://www.aadsm.org/docs/jdsm.10.10.2020o2.pdf. Accessed May 24, 2021. 


\section{SUBMISSION \& CORRESPONDENCE INFORMATION}

Submitted April 22, 2021

Submitted in final revised form June 22, 2021

Accepted for publication June 27, 2021

Address correspondence to: Michael Simmons, DMD, MSc, MPH. 16500 Ventura Blvd. Ste 370, Encino, CA

91436, USA. Email: info@ drmsimmons.com

\section{DISCLOSURE STATEMENT}

The authors report no conflicts of interest. 